\title{
KAJIAN IKATAN HIDROGEN DAN KRISTALINITAS KITOSAN DALAM PROSES ADSORBSI ION LOGAM PERAK (Ag)
}

\author{
Purnawan, C.*, Wibowo, A.H., Samiyatun \\ Jurusan Kimia, Fakultas Matematika dan Ilmu Pengetahuan Alam, \\ Universitas Sebelas Maret, Surakarta \\ Email: candra_pr@yahoo.com
}

\begin{abstract}
ABSTRAK
Telah dilakukan kajian tentang ikatan hidrogen inter dan intramolekuler kitosan yang dapat menyebabkan perubahan keteraturan dan tingkat kristalinitas polimer kitosan akibat masuknya ion logam Ag ke dalam polimer kitosan. Hasil penelitian menunjukkan bahwa masuknya ion logam $\mathrm{Ag}$ ke dalam polimer kitosan dapat mempengaruhi mempengaruhi ikatan hidrogen inter dan intramolekuler sehingga menyebabkan perubahan keteraturan dan tingkat kristalinitas polimer kitosan. Kristalinitas kitosan meningkat hingga perbandingan $\mathrm{Ag} / \mathrm{kitosan}=0.25 / 100(\mathrm{~b} / \mathrm{b})$. Setelah perbandingan $\mathrm{Ag} / \mathrm{kitosan}$ lebih besar dari 0.25/100 (b/b), kristalinitas kitosan menurun.
\end{abstract}

Kata kunci : kitosan, Ag, ikatan hidrogen, kristalinitas

\section{STUDY OF HYDROGEN BOND AND CRYSTALLINITY OF CHITOSAN IN ADSORPTION OF ION SILVER (Ag)}

\begin{abstract}
Influence of silver (Ag) ion toward inter and intramoleculer hydrogen bond of chitosan that change of chitosan crystallinity had been conducted. The results showed that introduction silver (Ag) ion into chitosan polimer had influenced of inter and intramoleculer hydrogen bond of chitosan so that crystallinity of chitosan was changed. Crystallinity of chitosan increased up to $0.25 / 100$ (w/w) composition of Ag/chitosan. Then, crystallinity of chitosan decreased with increasing composition of $\mathrm{Ag} /$ chitosan more than $0.25 / 100(\mathrm{w} / \mathrm{w})$.
\end{abstract}

Keywords: chitosan, Ag, hydrogen bond, crystallinity

\section{PENDAHULUAN}

Kitosan merupakan polimer kationik alami yang bersifat nontoksik, dapat mengalami biodegradasi dan bersifat biokompatibel. Kitosan juga dapat memiliki kegunaan yang sangat luas dalam kehidupan sehari-hari misalnya sebagai adsorben limbah logam berat dan zat warna, antijamur, kosmetik, farmasi, flokulan, antikanker, dan antibakteri (Lee dkk., 1999; Liu dkk., 2006; Prashanth dan Tharanathan, 2007;
Purnawan, dkk., 2008; Ramachandran dkk., 2003; Stephen, 1995). Ramachandran (2003) merekomendasikan beberapa senyawa yang dapat digunakan sebagai bahan antibakteri pada kain, yaitu: oksidator (aldehida dan halogen), produk triklosan yang berfungsi sebagai disinfektan, senyawa ammonium kuaterner, senyawa kompleks logam $(\mathrm{Cd}, \mathrm{Ag}$ dan $\mathrm{Cu}$ ), kitosan sebagai bahan antibakteri alami. Kitosan merupakan polikationik yang 
dapat berinteraksi dengan sel, enzim atau matrik polimer yang bermuatan negatif (Stephen, 1995). Adanya gugus aktif amina terprotonasi, hidroksil dan aktifitas hidrofobisitas memungkinkan untuk menghambat dan membunuh bakteri (Kim dkk., 2002; Liu dkk., 2006; Prashanth dan Tharanathan dkk., 2007; Washino dalam Kim dkk., 1998). Sifat antibakteri kitosan dapat ditingkatkan dengan penambahan logam $\mathrm{Ag}$ yang memiliki sifat antibakteri ke dalam kitosan melalui proses adsorpsi, baik yang diperoleh dari limbah yang mengandung $\mathrm{Ag}$ ataupun larutan $\mathrm{Ag}$ yang dibuat dalam laboratorium.

Masuknya logam Ag ke dalam polimer kitosan mempengaruhi ikatan hidrogen inter dan intramolekuler kitosan yang dapat menyebabkan perubahan keteraturan dan tingkat kristalinitas polimer kitosan. Perubahan keteraturan dan tingkat kristalinitas polimer kitosan ini dapat mempengaruhi sifat antibakteri kitosan. Oleh karena itu, perlu dilakukan kajian untuk mengetahui pengaruh adanya logam Ag terhadap keteraturan dan kristalinitas polimer kitosan sehingga dapat memberikan pengetahuan lebih lanjut tentang hubungan keteraturan dan kristalinitas polimer kitosan terhadap sifat antibakteri kitosan.

\section{METODE PENELITIAN}

\section{Alat dan Bahan}

Alat-alat yang digunakan antara lain: Spektrofotometer X-Ray Diffraction (Shimadzu XRD-6000), Spektrofotometer inframerah (FT-IR, Shimadzu PC 8201), Spektrofotometer Serapan Atom (AAS, Shimadzu AA6650F), Oven (Memmert), Neraca analitis (Sartorius BP 110), Stop watch, Pengaduk magnetik, Desikator, Alat - alat gelas.

Bahan-bahan yang digunakan antara lain: kitosan limbah cangkang udang (DD>90\%), $\quad \mathrm{AgNO}_{3}, \quad$ akuades, kertas saring.

\section{Prosedur penelitian}

Sebanyak $10 \mathrm{~mL}$ larutan $\mathrm{AgNO}_{3}$ dengan variasi konsentrasi 5, 10, 25, 50, 100, 200, 400, dan $1000 \mathrm{mg} / \mathrm{L}(0,05 / 100$; $0,1 / 100 ; 0,25 / 100 ; 0,5 / 100 ; 1 / 100 ; 2 / 100$; 4/100; 100/100 (b/b)) ditambahkan ke dalamnya sebanyak $100 \mathrm{mg}$ kitosan dan diaduk selama 18 jam. Kemudian filtrat dan residu dipisahkan dengan disaring. Residu dicuci dengan akuades dan dikeringkan dengan dioven pada suhu 70 ${ }^{\mathrm{O}} \mathrm{C}$ selama 3 jam. Kadar Ag yang tersisa dalam filtrate diukur dengan spektrofotometer serapan atom (AAS) untuk mengetahui kondisi optimum proses adsorpsi kitosan terhadap logam Ag sedangkan residu kitosan dikarakterisasi menggunakan FT-IR, dan XRD.

\section{HASIL DAN PEMBAHASAN}

\section{Proses adsorbsi}

Proses adsorbsi logam Ag oleh kitosan dilakukan pada berbagai perbandingan Ag-kitosan (b/b) kemudian ditentukan persen (\%) adsorbsi optimum kitosan terhadap logam Ag. Penentuan logam Ag dianalisis menggunakan AAS dengan metode kurva standart. Kurva standart dan persentase (\%) adsorbsi logam $\mathrm{Ag}$ oleh kitosan disajikan pada Gambar 1 dan 2. Berdasarkan Gambar 2 terlihat bahwa persen adsorbsi yang optimum terletak pada perbandingan Agkitosan 1/100 (b/b). Adsorbsi logam Ag oleh kitosan diperkirakan akan mempengaruhi beberapa karakter dari kitosan itu sendiri seperti keteraturan dan tingkat kristalinitas polimer kitosan yang dipengaruhi oleh ikatan hidrogen inter dan intramolekuler. 


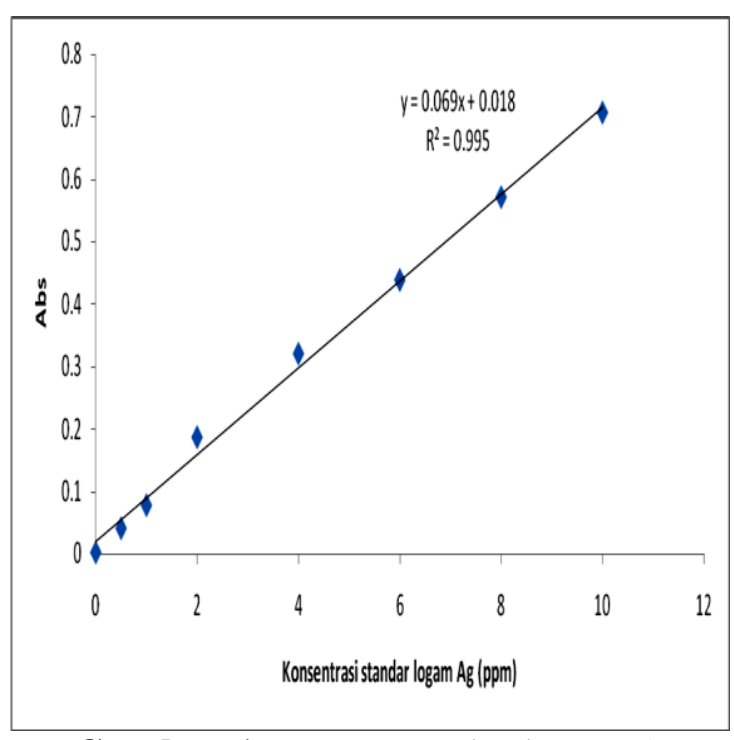

Gambar 1. Kurva standar logam Ag menggunakan AAS

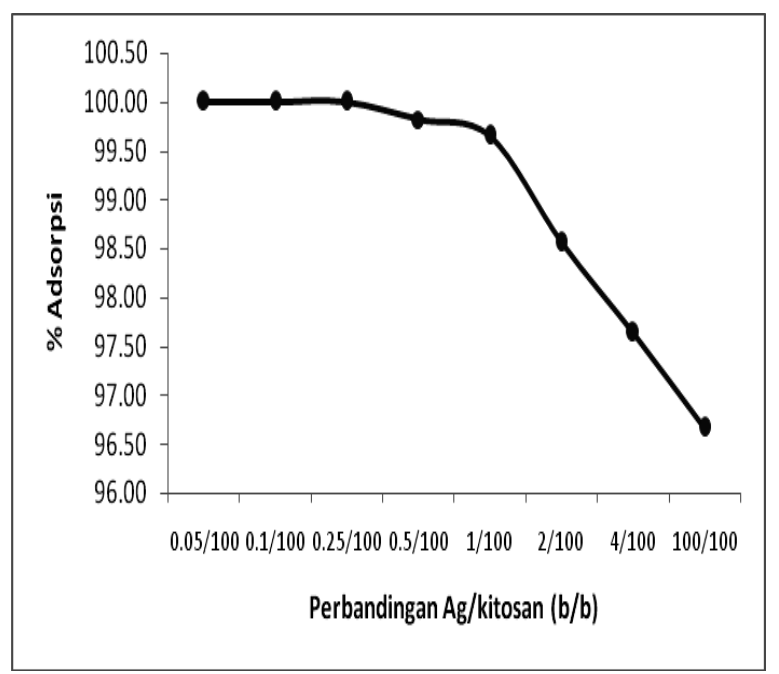

Gambar 2. Persentase (\%) adsorbsi logam Ag oleh kitosan

\section{Karakterisasi IR komposit kitosan-Ag}

Masuknya logam Ag ke dalam molekul kitosan akan menyebabkan perubahan karakter spektra IR dari kitosan. Berdasarkan perubahan tersebut, gugus fungsi kitosan yang berinteraksi dengan logam $\mathrm{Ag}$ dapat dianalisa. Perubahan spektra IR kitosan dengan variasi penambahan logam $\mathrm{Ag}$ dapat dilihat pada Gambar 3 dimana terlihat adanya perubahan dan pergeseran puncak-puncak tertentu dari spektra IR kitosan.

Serapan vibrasi sekitar $3448 \mathrm{~cm}^{-1}$ menunjukkan overlaping vibrasi $-\mathrm{NH}_{2}$ dan $-\mathrm{OH}$. Adanya sedikit penyempitan peak daerah sekitar $3448 \mathrm{~cm}^{-1}$ mengindikasikan bahwa terdapat reduksi kekuatan ikatan hidrogen yang dibentuk oleh kedua gugus tersebut dengan molekul air karena adanya ion logam Ag. Adanya ion logam Ag merubah sifat asam-basa Lewis dari atom $\mathrm{O}$ dan $\mathrm{N}$. Atom $\mathrm{O}$ dan $\mathrm{N}$ yang semula sangat elektronegatif dan begitu kuat dalam menarik pasangan electron (lebih bersifat asam Lewis) akan berubah menjadi basa Lewis dengan mendonorkan pasangan elektronnya ke dalam orbital ion logam $\mathrm{Ag}$. Hal ini menyebabkan gaya tarik atom $\mathrm{O}$ dan $\mathrm{N}$ terhadap elektron berkurang serta akhirnya akan menyebabkan lemah/hilangnya ikatan hidrogen yang ada. 


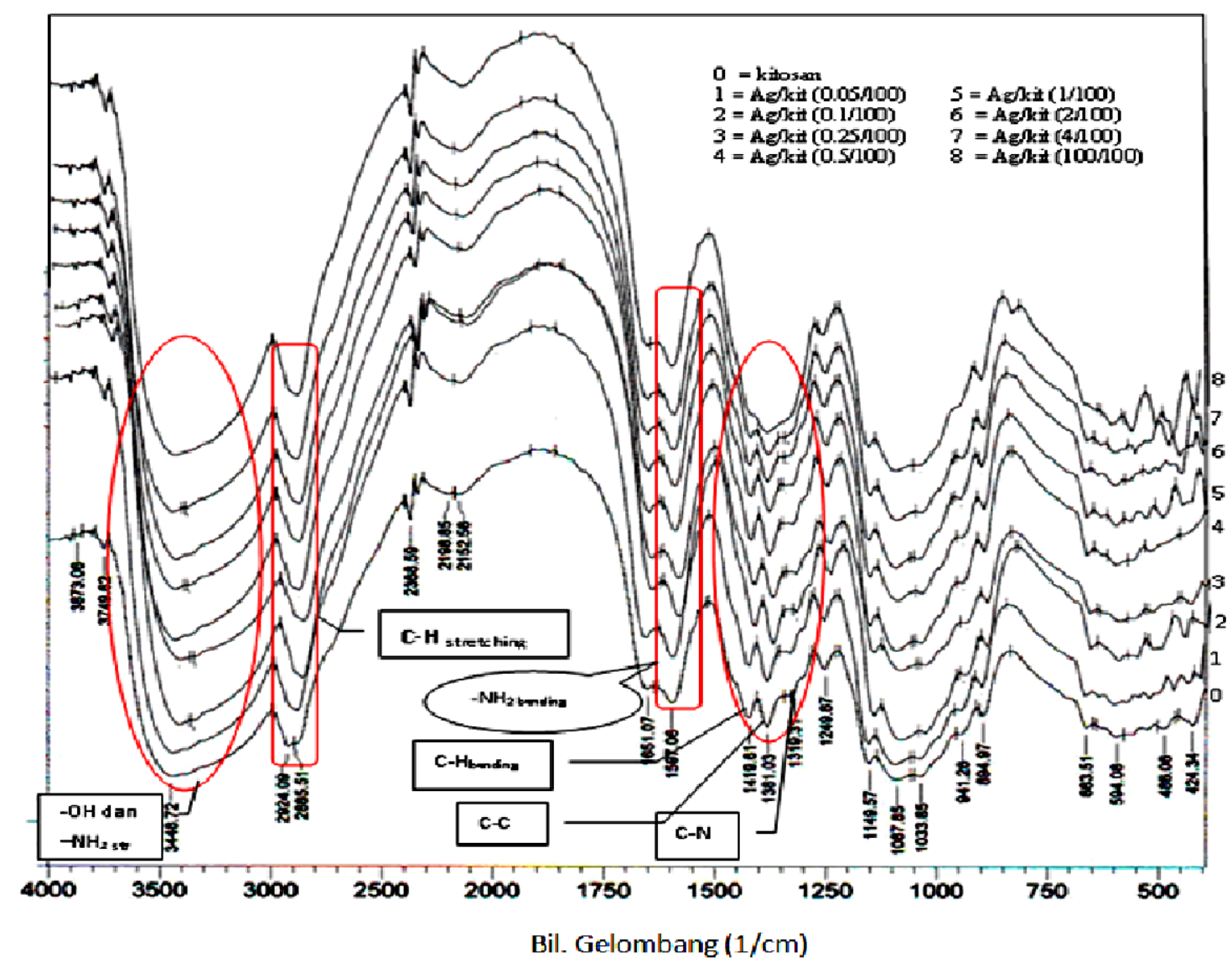

Gambar 3. Perubahan spektra IR kitosan setelah adanya variasi konsentrasi logam Ag

Selain itu sebelum terdapat logam $\mathrm{Ag}$, vibrasi $\mathrm{C}-\mathrm{H}$ stretching berupa serapan doublet yaitu serapan pada daerah sekitar 2924 dan $2885 \mathrm{~cm}^{-1}$. Peak doublet menunjukkan bahwa vibrasi gugus $\mathrm{C}-\mathrm{H}$ stretching dipengaruhi minimal 2 lingkungan yang berbeda cukup signifikan sehingga memunculkan 2 vibrasi stretching dengan energi berbeda. Setelah adanya logam Ag, terdapat perubahan serapan vibrasi $\mathrm{C}-\mathrm{H}$ stretching dari doublet menjadi singlet yang menunjukkan berkurangnya intensitas/hilangnya salah satu vibrasi C$\mathrm{H}$ stretching. Vibrasi $\mathrm{C}-\mathrm{H}$ stretching yang hilang adalah daerah serapan 2924 $\mathrm{cm}^{-1}$ yang kemungkinan dipengaruhi oleh atau dekat dengan gugus $-\mathrm{OH}$ dan $-\mathrm{NH}_{2}$. Adanya interaksi logam $\mathrm{Ag}$ dengan gugus $-\mathrm{OH}$ dan $-\mathrm{NH}_{2}$ kitosan ini juga menyebabkan kekakuan struktur molekul kitosan sehingga mengakibatkan turunnya intensitas serapan vibrasi gugus C-H pada daerah serapan sekitar 2924 dan $1419 \mathrm{~cm}^{-1}$, gugus $\mathrm{C}-\mathrm{C}$ pada daerah serapan sekitar $1381 \mathrm{~cm}^{-1}$, gugus $\mathrm{C}-\mathrm{N}$ pada daerah serapan sekitar $1319 \mathrm{~cm}^{-1}$. Berdasarkan perubahan-perubahan di atas, terlihat bahwa gugus fungsi kitosan yang berinteraksi dengan logam $\mathrm{Ag}$ adalah gugus $-\mathrm{OH}$ dan $-\mathrm{NH}_{2}$.

\section{Karakterisasi XRD komposit kitosan-Ag}

Selain menyebabkan perubahan karakter spektra IR kitosan, adanya logam Ag juga mempengaruhi kristalinitas kitosan seperti yang terlihat pada perubahan difraktogram kitosan Gambar 4. 


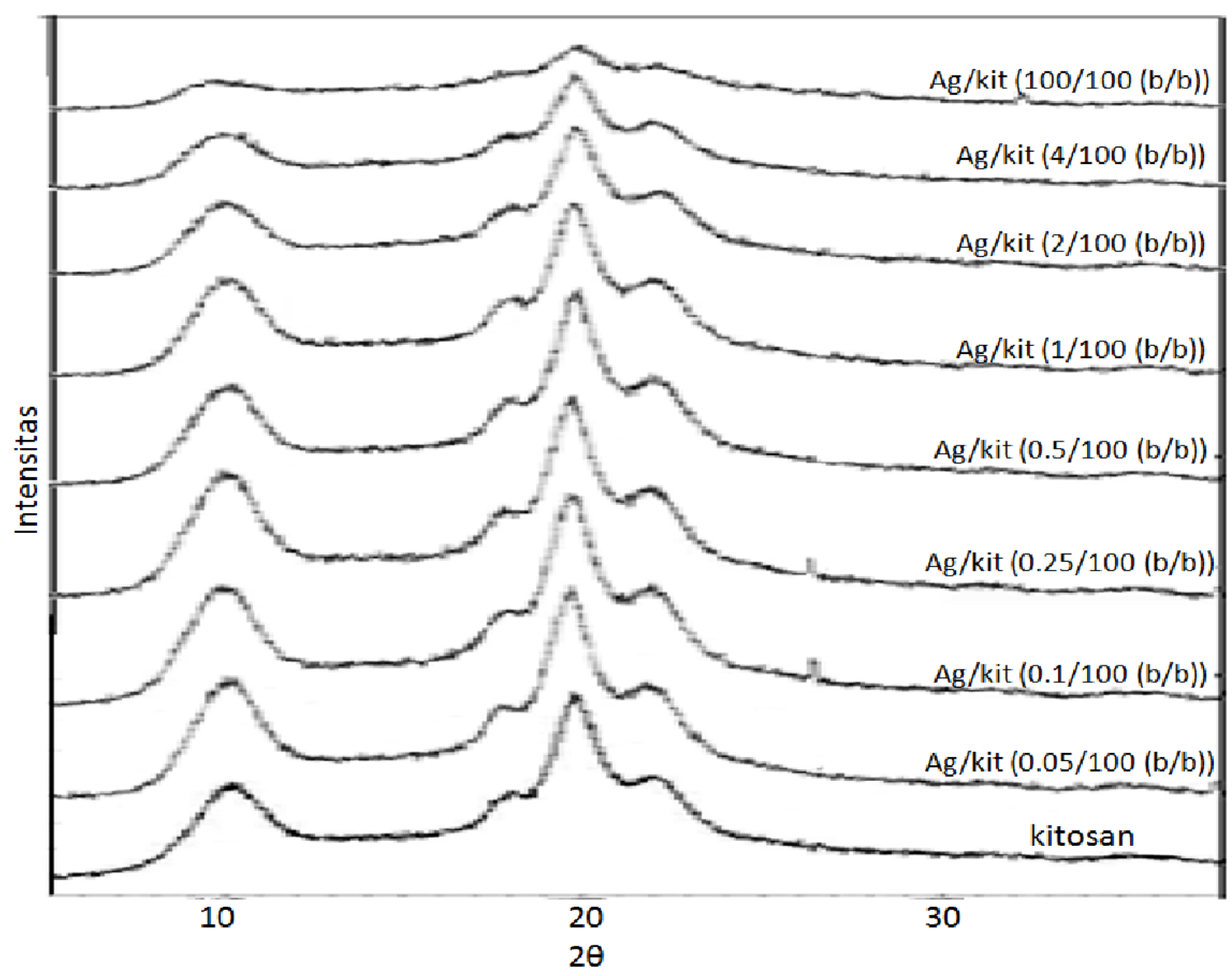

Gambar 4. Perubahan difraktogram kitosan setelah adsorpsi logam Ag

Berdasarkan Gambar 4, terlihat bahwa tinggi puncak utama dari difraktogram XRD kitosan yaitu $2 \theta=10^{\circ}$ dan $20^{\circ}$ cenderung mengalami perubahan dengan adanya variasi konsentrasi logam Ag. Hal ini menunjukkan adanya perubahan kristalinitas kitosan. Perubahan ini juga didukung oleh perubahan intensitas puncak utama dari difraktogram XRD kitosan seperti yang terlihat pada Gambar 5.

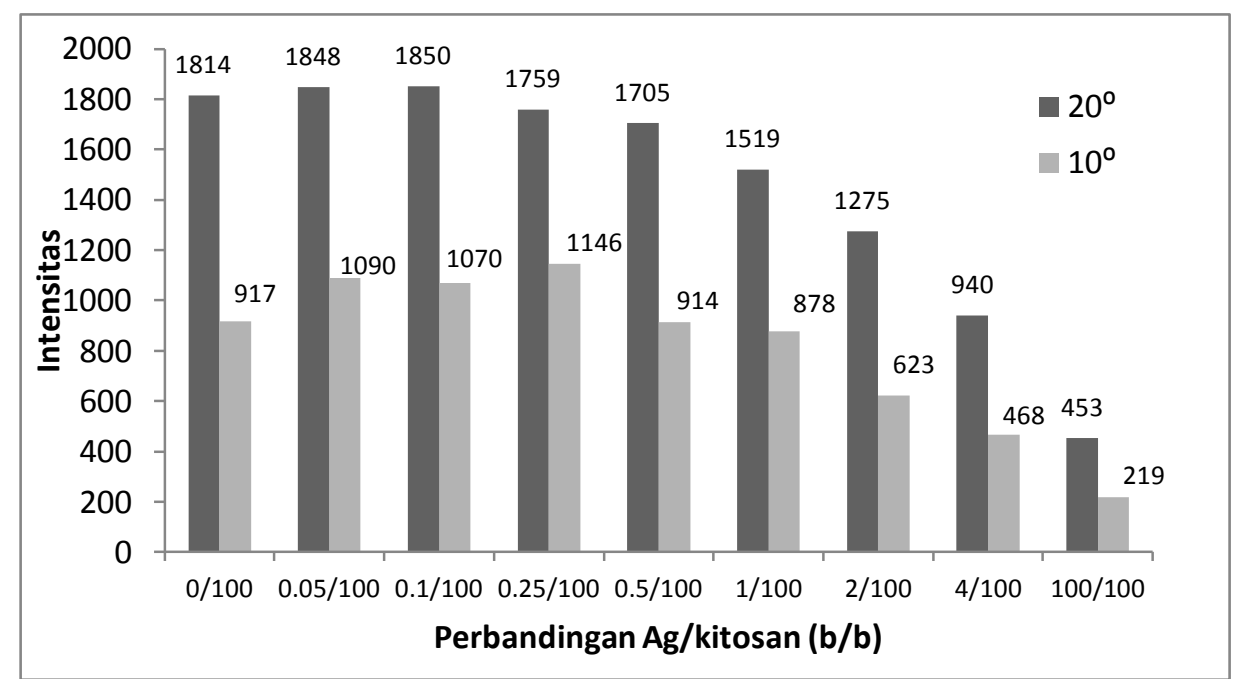

Gambar 5. Perubahan intensitas puncak utama difraktogram kitosan 
Kristalinitas kitin dan kitosan sangat dipengaruhi kekuatan ikatan hidrogen intramolekuler dan intermolekuler polimer kitin dan kitosan (Champagne, 2002; Zhang dkk., 2005). Selama proses pembentukan kitosan sangat dimungkinkan terjadinya pemutusan ikatan glikosida dan deasetilasi secara acak sehingga menyebabkan heterogenitas struktur maupun panjang rantai polimer kitosan tinggi. Heterogenitas struktur dan rantai polimer kitosan menyebabkan penurunan kekuatan ikatan hidrogen intramolekuler dan intermolekuler kitosan serta memberikan perubahan keteraturan unit polimer maupun antar unit polimer kitosan sehingga akhirnya akan mempengaruhi orientasi bidang kristal dan penurunan derajat kristalinitas kitosan. Jika digabungkan dengan data perubahan spektra IR kitosan, maka kekuatan ikatan hidrogen intramolekuler dan intermolekuler kitosan dipengaruhi oleh gugus $-\mathrm{OH}$ dan $-\mathrm{NH}_{2}$. Ikatan hidrogen intramolekuler dan intermolekuler kitin dan kitosan seperti yang terlihat pada Gambar 6 dan 7.

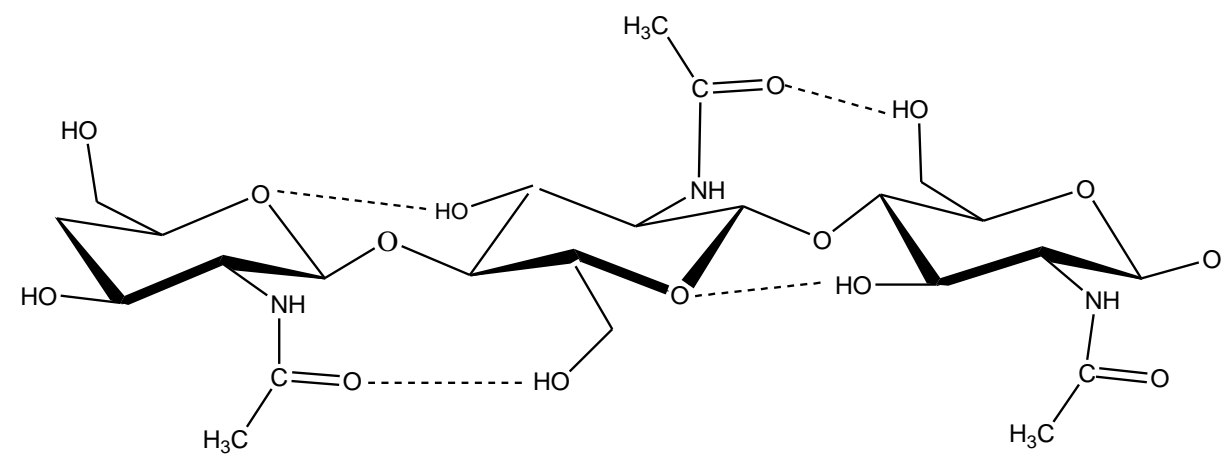

Gambar 6. Ikatan hidrogen intramolekuler

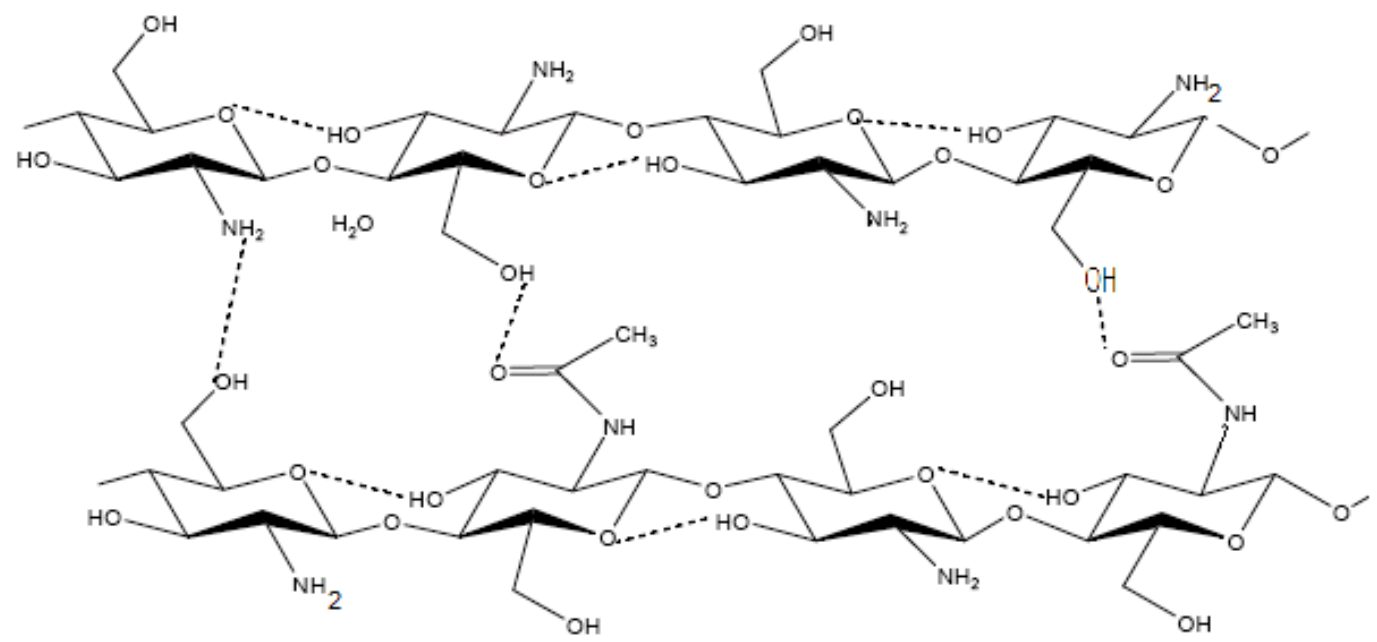

Cat: kitin atau kitosan tergantung pada perbandingan gugus amina dan asetil yang ada dalam polimer

Gambar 7. Ikatan hidrogen intermolekuler 
Adanya proses substitusi gugus asetil menjadi gugus amina primer menyebabkan berkurangnya ikatan hidrogen intramolekuler dan intermolekuler yang diperankan oleh gugus $-\mathrm{OH}$ dan $-\mathrm{NH}_{2}$ sehingga kristalinitas kitosan menurun. Adanya proses substitusi gugus asetil menjadi gugus amina primer dapat menyebabkan gugus amina primer tidak dapat membentuk ikatan hidrogen intramolekuler karena jarak terlalu jauh. Sedangkan ikatan hidrogen intermolekuler yang diperankan oleh gugus $-\mathrm{OH}$ dan $-\mathrm{NH}_{2}$ akan berkurang/hilang dengan adanya proses deasetilasi secara acak seperti yang terlihat pada Gambar 7. Proses deasetilasi di atas $90 \%$ menyebabkan berkurangnya ikatan hidrogen intramolekuler lebih besar daripada berkurangnya ikatan hidrogen intermolekuler.

Adanya logam Ag dengan konsentrasi kecil dapat berfungsi sebagai penghubung dan pengganti ikatan hidrogen intramolekuler dan intermolekuler yang hilang sehingga mampu meningkatkan kristalinitas kitosan. Fungsi logam Ag sebagai penghubung dan pengganti ikatan hidrogen intramolekuler dan intermolekuler diilustrasikan seperti Gambar 8 dan 9.

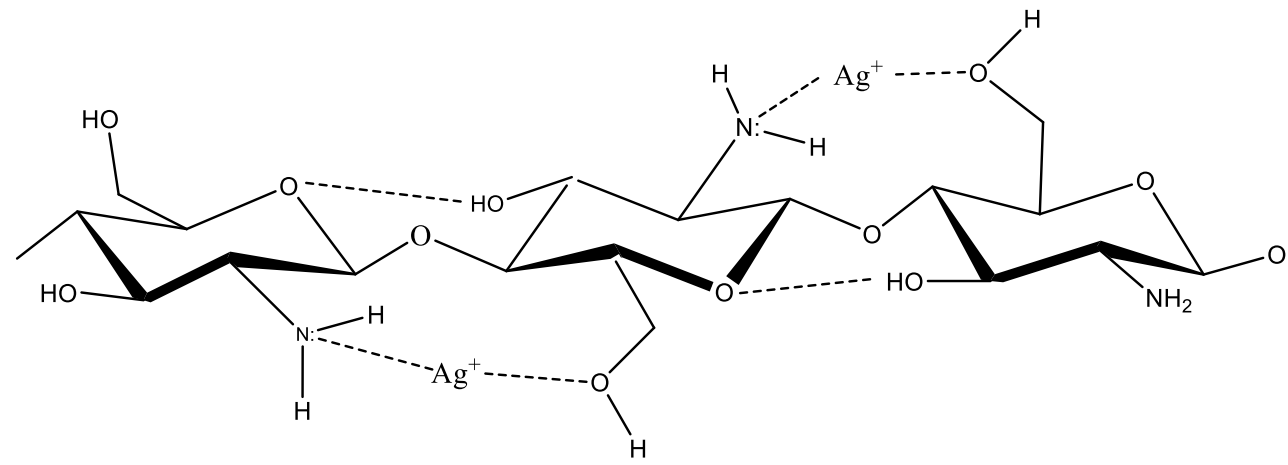

Gambar 8. Fungsi logam Ag sebagai pengganti ikatan hidrogen intramolekuler

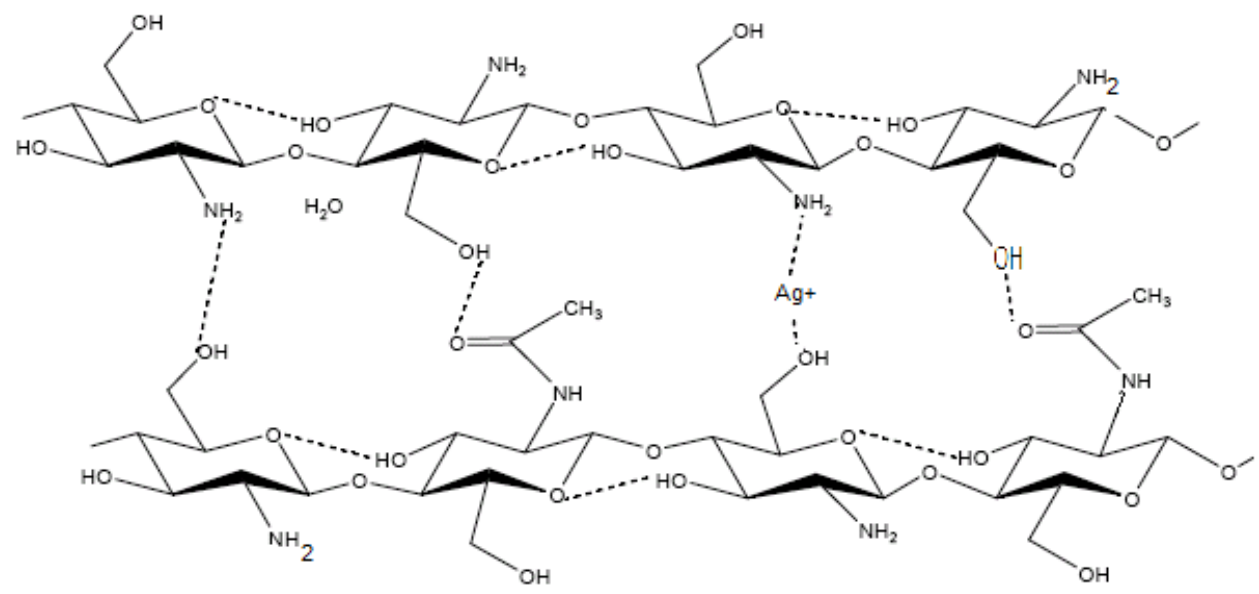

Gambar 9. Fungsi logam Ag sebagai pengganti ikatan hidrogen intermolekuler 
Dikarenakan ikatan hidrogen intramolekuler lebih banyak yang hilang daripada ikatan hidrogen intermolekuler, maka secara otomatis logam Ag yang dibutuhkan untuk meningkatkan keteraturan bidang kristal yang disebabkan oleh ikatan hidrogen intramolekuler lebih banyak daripada logam Ag yang dibutuhkan untuk meningkatkan keteraturan bidang kristal yang disebabkan oleh ikatan hidrogen intermolekuler. Jika dilihat dari data perubahan intensitas puncak-puncak utama kitosan, puncak sekitar $2 \theta=10^{\circ}$ lebih banyak membutuhkan logam $\mathrm{Ag}$ untuk meningkatkan keteraturan bidang kristal pada puncak sekitar $2 \theta=10^{\circ}$ daripada pada puncak $2 \theta=20^{\circ}$. Hal ini mengindikasikan bahwa puncak sekitar $2 \theta=10^{\circ}$ lebih banyak dipengaruhi oleh ikatan hidrogen intramolekuler sedangkan puncak sekitar $2 \theta=20^{\circ}$ lebih banyak dipengaruhi oleh ikatan hidrogen intermolekuler. Intensitas puncak sekitar $2 \theta=10^{\circ}$ memiliki kecenderungan meningkat hingga perbandingan Ag:kitosan 0.25/100 sedangkan intensitas puncak sekitar $2 \theta=20^{\circ}$ memiliki kecenderungan meningkat hingga perbandingan Ag:kitosan 0.1/100.

Namun, adanya logam Ag dengan konsentrasi yang relatif besar dapat menyebabkan penurunan kristalinitas kitosan dengan merusak ikatan hidrogen intramolekuler dan intermolekuler yang ada. Intensitas puncak sekitar $2 \theta=10^{\circ}$ mengalami penurunan setelah perbandingan Ag:kitosan $\quad 0.25 / 100$ sedangkan intensitas puncak sekitar $2 \theta=$ $20^{\circ}$ mengalami penurunan setelah perbandingan Ag:kitosan $\quad 0.1 / 100$ (Gambar 4 dan 5). Adanya konsentrasi logam Ag yang besar menyebabkan gugus $-\mathrm{OH}$ dan $-\mathrm{NH}_{2}$ lebih cenderung membentuk khelat dengan logam $\mathrm{Ag}$ secara sendiri-sendiri sehingga logam Ag tidak lagi berfungsi sebagai penghubung dan pengganti ikatan hidrogen intramolekuler dan intermolekuler kitosan, tetapi akan merusak ikatan hidrogen intramolekuler dan intermolekuler yang ada seperti yang diilustrasikan oleh Gambar 10.

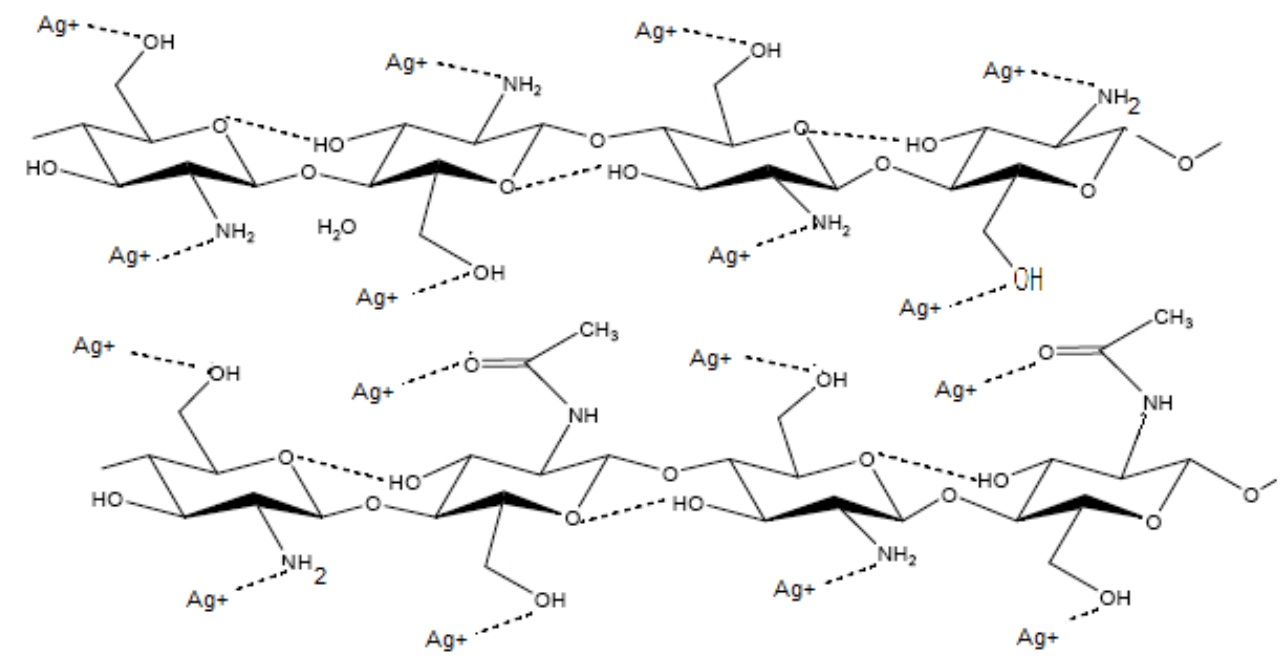

Gambar 10. Berkurangnya ikatan hidrogen intramolekuler dan intermolekuler kitosan 


\section{KESIMPULAN}

Berdasarkan hasil dan pembahasan di atas, masuknya logam $\mathrm{Ag}$ ke dalam polimer kitosan dapat mempengaruhi mempengaruhi ikatan hidrogen inter dan intramolekuler sehingga menyebabkan perubahan keteraturan dan tingkat kristalinitas polimer kitosan. Kristalinitas kitosan cenderung meningkat hingga perbandingan Ag:kitosan 0.25/100 (b/b) dan setelah perbandingan Ag:kitosan lebih besar dari $0.25 / 100 \quad(\mathrm{~b} / \mathrm{b})$, kristalinitas kitosan menurun.

\section{DAFTAR PUSTAKA}

Champagne, L.M., 2002, The Synthesis of Water Soluble N-Acyl Chitosan Derivatives for Charaterization as Antibacterial Agent, A desesertation, B.S. Xavier University of Louisiana, Louisiana

Kim, C.H., and Choi, K.S., 2002, Synthesis and Antibacterial Activity of Quaternised Chitosan Derivatives Having Different Methyene Spacers, J. Ind. Eng. Chem., 8(1): 71 76.

Kim, Y.H., Choi, H.M., and Yoon, J.H., 1998, Synthesis of a Quaternary Ammonium Derivative of Chitosan and Its Application to a Cotton Antimicrobial Finish, Text. Res. J., 68(6): $428-434$.

Lee, S., Cho, J.S., and Cho, G., 1999, Antimicrobial and Blood repellent Finishes for Cotton and Nonwoven Fabrics Based on Chitosan and Fluoropolymers, Text. Res. J., 69(2): $104-112$
Liu, N., Chen, X.G., Park, H.J., Liu, C.G., Liu, C.S., Meng, X.H., and $\mathrm{Yu}$, L.J., 2006, Effect of MW and Concentration of Chitosan on Antibacterial Activity of Escherichia Coli, Carbohydr. Polym., 64: 60 65.

Prashanth, K.V.H., and Tharanathan, R.N., 2007, Chitin/Chitosan Modifications and Their Unlimited Application Potential-An Overview, Food Sci. Tech., 18:117-131

Purnawan, C., 2008, Thesis, Kitosan dari Cangkang Udang dan Aplikasi Kitosan sebagai Bahan Antibakteri pada Kain Katun, Universitas Gadjah Mada, Yogyakarta.

Ramachandran, T., Rajendrakumar, K., and Rajendran, R., 2003, Antimicrobial Textiles - an Overview, IE(I) Journal-TX, 84: $42-47$.

Stephen, A.M., 1995, Food Polysaccharides and Their Application, University of Cape Town, Marcel Dekker, Inc, Rondebosch, 442-450.

Zhang, Y.Q., Xue, C., Xue, Y., Gao, R., and Zhang, X., 2005, Determination of The Degree of Deacetylation of Chitin and Chitosan by X-ray Powder Diffaction, Carbohydr. Res., 340: $1914-1917$ 